\title{
A Six Sigma Trial For Reduction of Error Rates in Pathology Laboratory
}

\author{
Zeynep TOSUNER, Zühal GÜciN, Tuğçe KIRAN, Nur BÜYÜKPINARBAŞILI, Seval TURNA, \\ Olcay TAŞKIRAN, Dilek Sema ARICI
}

Department of Pathology, Bezmialem Foundation University School of Medicine, ISTANBUL, TURKEY

\begin{abstract}
Objective: A major target of quality assurance is the minimization of error rates in order to enhance patient safety. Six Sigma is a method targeting zero error (3.4 errors per million events) used in industry. The five main principles of Six Sigma are defining, measuring, analysis, improvement and control. Using this methodology, the causes of errors can be examined and process improvement strategies can be identified. The aim of our study was to evaluate the utility of Six Sigma methodology in error reduction in our pathology laboratory.

Material and Method: The errors encountered between April 2014 and April 2015 were recorded by the pathology personnel. Error follow-up forms were examined by the quality control supervisor, administrative supervisor and the head of the department. Using Six Sigma methodology, the rate of errors was measured monthly and the distribution of errors at the preanalytic, analytic and postanalytical phases was analysed. Improvement strategies were reclaimed in the monthly intradepartmental meetings and the control of the units with high error rates was provided.
\end{abstract}

Results: Fifty-six (52.4\%) of 107 recorded errors in total were at the pre-analytic phase. Forty-five errors (42\%) were recorded as analytical and 6 errors (5.6\%) as post-analytical. Two of the 45 errors were major irrevocable errors. The error rate was 6.8 per million in the first half of the year and 1.3 per million in the second half, decreasing by $79.77 \%$.

Conclusion: The Six Sigma trial in our pathology laboratory provided the reduction of the error rates mainly in the pre-analytic and analytic phases.

Key Words: Pathology, Quality improvement, Six sigma

\section{INTRODUCTION}

The "quality system" terminology originates from ISO 9000 Quality Standards that have been used in business life and industry. A Quality system comprises organizational structure, liabilities, procedures, operations and sources that are required for quality management. This system has also been modified for medical sciences (1). Laboratory medicine specialists emphasized the quality control model in daily operations such as instrument calibration and validation, reagent performance, linearity measurements, and result output. Total quality management including policies, written documents, organization, personnel, equipment and safety has been applied in pathology laboratories worldwide (2). Studies concerning quality management improvement and standardization have also taken place in the medical literature in Turkey $(3,4)$.

Six Sigma have been used in industrial sciences for regulating validity according to statistical analyses and improving quality and minimizing errors in operation

(Turk Patoloji Derg 2016, 32:171-177)

Received : 28.02.2016 Accepted : 28.03.2016 processes. Six Sigma was first used by a Japanese company in the 70s for decreasing the error rate. The five main principles of Six Sigma are: 1. Defining, 2. Measuring, 3. Analysis, 4. Improving, and 5. Control.

It is suggested that Six Sigma can have positive impacts on efficiency of laboratory safety $(2,5)$. Six Sigma approach in laboratory medicine was first tested in pathology, and the data of Q-Probes Program created by College of American Pathologists are present in literature (6-8).

Six Sigma is a procedure of detecting errors used for the purpose of improvement under the roof of total quality management. Six Sigma is a methodology targeting zero error (3.4 errors per million events). This method has also been used as a statistical term demonstrating a process' degree of deviation from excellence. Six Sigma enables the determination of the number of defects per million events via monitorizing the processes. The error risk per million events is called the "process Sigma level". The process Sigma level demonstrates the quantity of value that the

Correspondence: Zeynep TOSUNER

Bezmiâlem Vakıf Üniversitesi Tip Fakültesi, Patoloji Anabilim Dalı, İSTANBUL, TURKEY

E-mail: zeyneptosuner@yahoo.com.tr Phone: +90 05327366951 
process has deceived. There is a close relation between the Sigma level and characteristics like error, cost of quality loss (repetitions, time loss, wrong therapy, morbidity and mortality, etc.) and efficiency per each test result. Elements of the processes are analyzed according to the process Sigma levels, and the area of improvement (AOI) is evaluated (9).

Total quality management application in surgical pathology laboratories is rapidly increasing. One of the main principles in quality management is the analysis and prevention of errors.

Errors in the pathology unit are classified as pre-analytic, analytic and post-analytic. Pre-analytic errors include errors during the process from entry to macroscopical analysis, and analytic errors include errors from macroscopic analysis to the reporting phase. Post-analytic errors include reporting/ diagnosis errors and the errors that occur after tissue processing procedures, such as the tissue disposal process, archiving, delivery of the reports, communication errors, laboratory information system errors, comprehensibility of the reports or misinterpretation errors. Most of the errors in routine pathology processes are easily recognized before sign out and are revocable; however, some are unidentified irrevocable errors harmful to the patient. Reporting errors in quality management is significant in terms of reducing the repetition of an error (10).

Several measurement and classification systems for errors are introduced in surgical pathology. A system that focuses on the clinical impact to the patient has been described by Raab et al. (11). In this system, errors were separated into two categories; major and minor errors. Major errors were subclassified in 4 categories causing no harm, near miss, harm and unknown in measure of clinical severity. Minimal harm was described as being associated with unnecessary, further noninvasive testing, or a delay in diagnosis or therapy of $<6$ months. The second category, mild harm, represented unnecessary but invasive further testing, a delay in diagnosis or therapy over 6 months, or minor morbidity due to this delay. The third category, moderate harm, included situations where moderate morbidity due to a delay in therapy or unnecessary therapy occurred due to the unjustified diagnosis. The last category, severe harm, included loss of life, limb, or other body part, and any longlasting morbidity of over 6 months $(11,12)$.

In our study, we aimed to examine all of major and minor errors that had been encountered in our department in a 1-year period and to assess the effect of Six Sigma implementation in error reduction and process improvement.

\section{MATERIALS and METHODS}

In our pathology laboratory, the ISO 9001 program is used as the standard program for quality management and 26,000 cases (16,000 biopsies and 10,000 cytology samples) are assessed in a year. Errors concerning both biopsy and cytology samples encountered between April 2014 and April 2015 were recorded.

Pathology personnel (specimen registery personnel, laboratory technical personnel, or pathologist) determined the error, and recorded the characteristics of the error in a follow-up form including his/her own errors. The standard form is shown in Figure 1.

Error follow-up forms were examined by the quality control supervisor, administrative supervisor and the head of the department. The causes of errors were investigated and revocable errors were corrected. Six Sigma principles were applied to the evaluation of problems in our department for 6 months.

In the defining phase, the causes and characteristics of problems and the damages they caused were investigated. The distribution of errors at pre-analytic, analytic and postanalytic phases was examined in the measuring phase. In the analysis phase, problem-solving activities were applied regarding the prevention of the occurrence of errors. Finally, the implementations for reducing all these errors were initiated in the improvement phase. An example of Six Sigma is presented in Figure 2.

Regarding these errors, intradepartmental meetings were held in monthly periods and error analyses were carried out. Extradepartmental meetings with the responsible clinical staff were organized in order to optimize sample delivery procedures. In the intradepartmental meetings, where the employees could express their problems and which were based on the possible legal dimensions of the errors, activities aiming to increase efficiency and to decrease errors were performed. In these meetings, the employees were given the opportunity to work in fields where they felt most productive and solution offers about the problems of employees were prioritized. With this purpose, not only was a quality file created which all employees of the pathology unit could access via their computers, but also a platform was formed where errors, critical-diagnosis, biopsy-cytology correlations, examination requests and the number of denied samples were handled.

Additionally, a double-checking control system was initiated in the phases of recording and macroscopy, macroscopy and embedding, embedding and sectioning, 


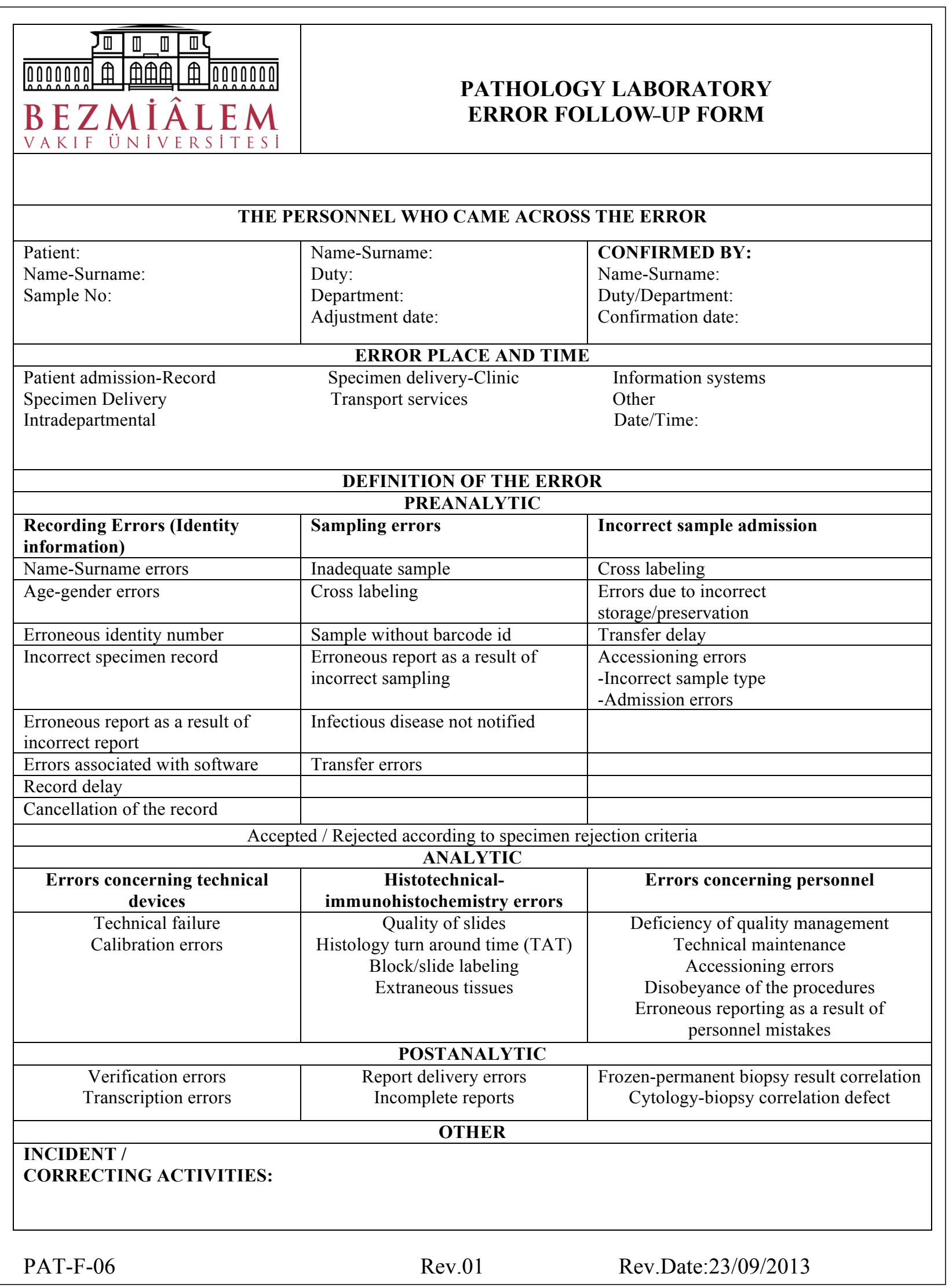

Figure 1: Pathology laboratory error follow-up form. 


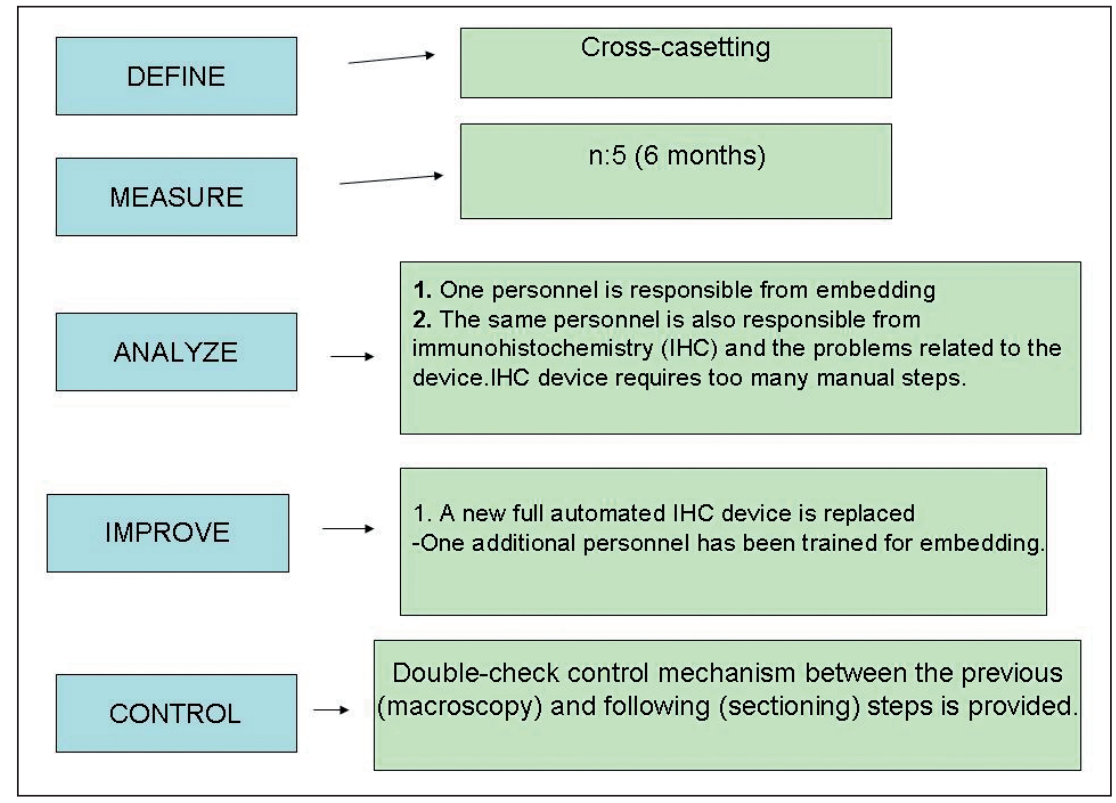

Figure 2: Implementation of Six Sigma method in the cross-cassetting problem.

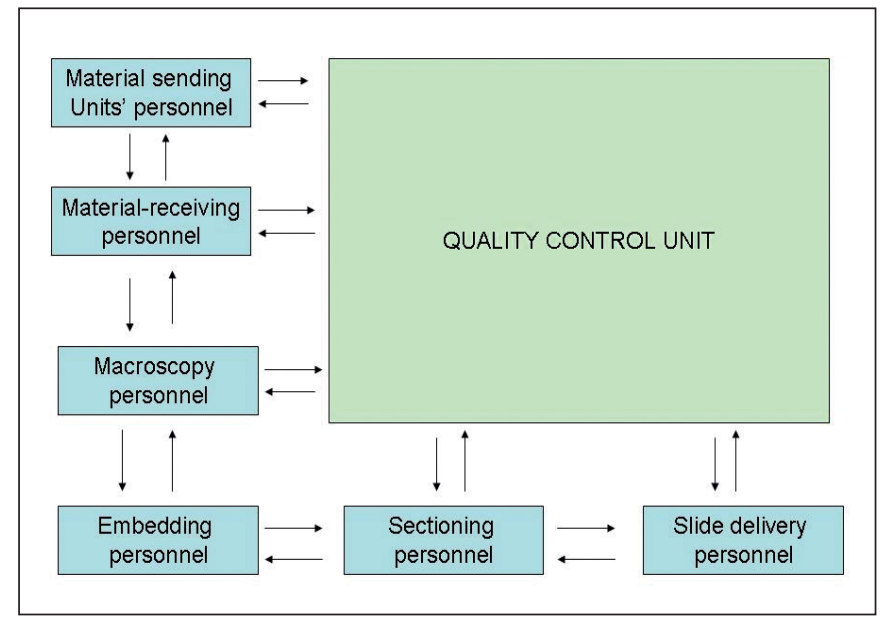

Figure 3: Schema of the intradepartmental double-checking system.

and the other operations after sectioning and the delivery of the slides. In this system, the technical personnel working in successive steps, such as reception staff and macroscopy staff, checked each other. For example, all of the recorded specimens were listed and checked by two staff members (delivery and reception staff). After recording, the list was also double-checked by the reception and macroscopy staff. In any problematic circumstance, the staff member in charge called the quality control supervisor. The quality control supervisor checked the materials and forms and communicated with the corresponding specialists of the clinical departments if needed. Hence all of the sub-units were double-checked and connected to the quality control unit (Figure 3).
The quality control supervisor also checked the quality of processing, sectioning and staining by checking 10 random slides prepared from different tissues every day.

The present immunohistochemistry staining machine was replaced with a new and more automated device.

In the control phase, units with high error rates were checked among employees.

\section{RESULTS}

Fifty-six (52.4\%) of 107 recorded errors in total were at the pre-analytic phase. Forty-five errors (42\%) were recorded as analytical and 6 errors (5.6\%) as post-analytical. Distribution of the errors with standard error classification codes $(12,13)$ in preanalytical, analytical and postanalytical phases are shown in Table I. The number of errors differed between each month and these are shown in Figure 4. The highest number of errors $(n=41)$ was detected in May 2014, while the lowest number was detected in August 2014, December 2014 and February 2015 (n=2). Eighty-nine errors were detected in the first semiannual period, while 18 were detected in the second semiannual period.

The overall error rate of our laboratory was $0.041 \%$ in 4.1 per million cases (107 errors per 26.000 cases) in one year. The error rate was 6.8 per million in the first half of the year and 1.3 per million in the second half.

Pre-analytic errors were subclassified into intradepartmentaland extradepartmentalerrors. Theintradepartmental error ratio was $58.3 \%$, while the extradepartmental ratio was $31.7 \%$. No errors regarding the cytology interpretationbiopsy correlation were recorded. 
Table I: The distribution of the errors in pre-analytical, analytical and postanalytical phases

\begin{tabular}{|c|c|c|c|}
\hline \multicolumn{2}{|c|}{ Pre-analytical phase n:56 } & \multirow{2}{*}{ Analytical phase n: 45} & \multirow{2}{*}{ Post-analytical phase n: 6} \\
\hline Intradepartmental n:35 & Nondepartmental n: 21 & & \\
\hline \multirow{2}{*}{$\begin{array}{l}\text { Specimen and patient } \\
\text { identification } \mathbf{n}: \mathbf{3 0}\end{array}$} & \multirow{2}{*}{ Specimen fixation n:12 } & $\begin{array}{l}\text { Frequency and causes of repeat } \\
\text { stains n:19 }\end{array}$ & \multirow{2}{*}{$\begin{array}{c}\text { Frozen section-permanent } \\
\text { section correlation error } \mathbf{n}: 2\end{array}$} \\
\hline & & $\begin{array}{l}\text { Histology turn around time } \\
\text { n:8 }\end{array}$ & \\
\hline \multirow{4}{*}{ Accessioning errors $\mathbf{n}: 5$} & \multirow{2}{*}{$\begin{array}{l}\text { Specimen and patient } \\
\text { identification } \mathbf{n}: \mathbf{8}\end{array}$} & Quality of histologic sections n:5 & \multirow{2}{*}{$\begin{array}{l}\text { Verification of errors during } \\
\text { electronic signout or report } \\
\text { finalization } \mathbf{n : 3}\end{array}$} \\
\hline & & Extraneous tissue $\mathrm{n}: 4$ & \\
\hline & \multirow[b]{2}{*}{ Specimen delivery $\mathbf{n : 1}$} & Block labeling n:7 & \multirow[b]{2}{*}{$\begin{array}{c}\text { Specimen discharging during } \\
\text { the routine examination } \\
\text { process } \mathbf{n}: \mathbf{1}\end{array}$} \\
\hline & & $\begin{array}{l}\text { Work environment problems } \\
\text { (refrigerator fault after power } \\
\text { failure, water deluge) } \mathbf{n}: 2\end{array}$ & \\
\hline
\end{tabular}

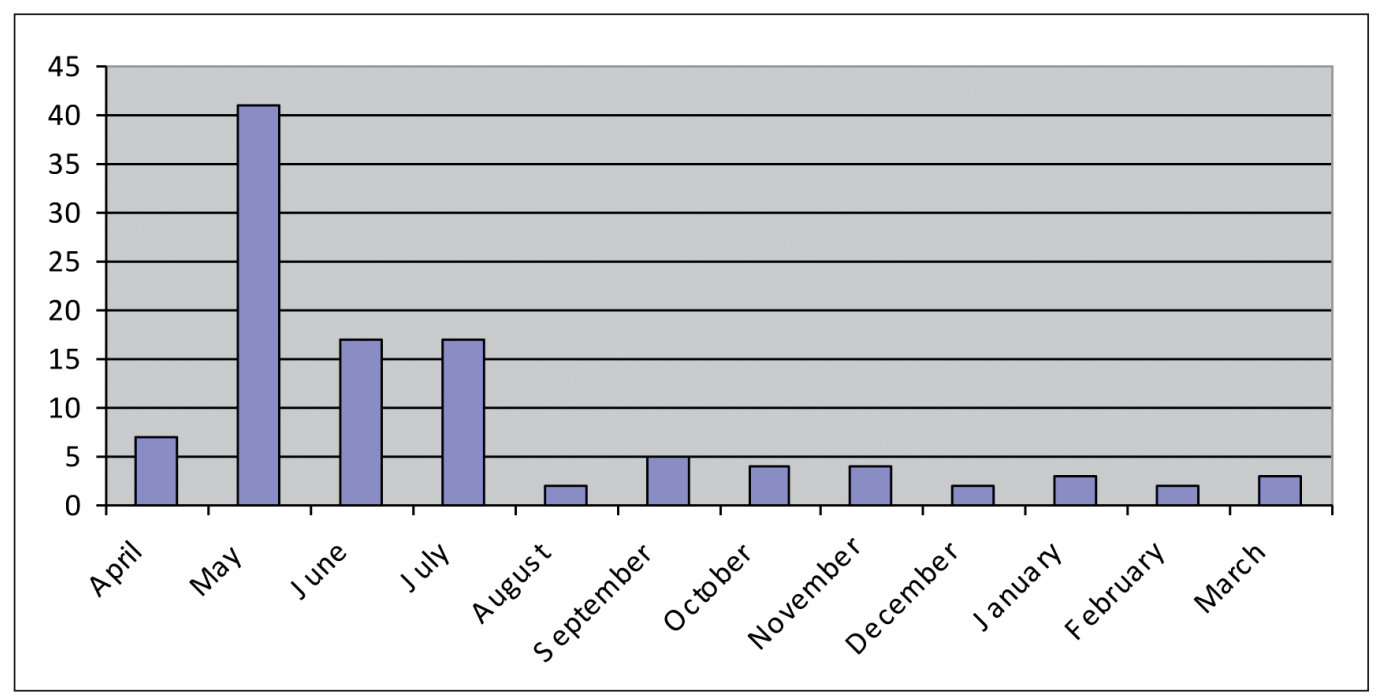

Figure 4: The distribution of the number of errors in one year.
Of the recorded 107 errors, 2 errors were major errors. One of the major errors was a pre-analytic phase error. A kidney core biopsy in two fragments was delivered to the pathology laboratory in frozen state in $10 \%$ formalin. Both routine examination and direct immunofluorescein application failed due to erroneous fixation and preservation. The patient underwent an additional biopsy procedure. The other major error was the discharge of a tonsillectomy specimen before the completion of the reporting process. This was noticed when the relevant pathologist wanted to receive additional pieces from the specimen for further evaluation. The specimen had accidentally been discharged by the macroscopy assistant. Further evaluation was available by application of an immunohistochemistry panel to the present two blocks of the specimen in order to exclude lymphoma. The final diagnosis of the case was chronic tonsillitis. The clinician of the patient was informed about the failure and follow-up of the patient was recommended. All of the remaining errors were minor errors and were corrected before the pathology report finalization.

The initial immunohistochemistry device required 2 hours of manual handling procedures. Technical problems were also encountered regarding the software system, and technical support was needed 4-5 times per month. The workload of technical personnel was reduced by $50 \%$ by moving to a more automated system that required 1 hour of manual handling procedures.

When the first semiannual and second semiannual periods were compared, the number of errors was 89 in the first semiannual period while this number was 18 in the second semiannual period, decreasing by $79.77 \%$. 


\section{DISCUSSION}

The Association of Directors of Anatomical and Surgical Pathology (ADASP) recommends the usage of Quality Assurance and Improvement plans and monitors in the pre-analytic, analytic and post-analytic phases in order to enhance patient safety, minimize error rates, ensure timely delivery of reports and monitor physician competence (13). A formal root cause analysis is recommended for incidents in which there is significant patient harm (14). Dhir et al described a multiple-step algorithm of a formal root cause in an incident in which there was an error in specimen accessioning. After the identification of errors, changes in procedures were implemented based on "oneby-one" accessioning (15).

In our institute we initiated the Six-Sigma trial as a formal root cause after the erroneous discharge of the tonsillectomy specimen that is stated as a major error in our study. Identification ("Defining") of the probable causes of errors provided the construction of the one by one accessioning double-checking system in the laboratory. Thanks to the implementation of this system, the error rates decreased by $79.77 \%$.

Organization of the intradepartmental and extradepartmental meetings provided training for the personnel on the main principles of pathology laboratory processing. Pereira et al. compared two 9-month periods during which a monthly anatomic pathology quality and safety conference was held and noticed a marked improvement in the second time period with fewer cases of incomplete examination, incorrect tumor classification, incorrect tumor staging and clinically significant incorrect diagnosis (16).

We observed the highest error rate $(52.4 \%)$ in the preanalytic phase. Pre-analytic component constitutes up to $80 \%$ of recorded cases based on a study revealing errors in a ISO 9002:1994 certified clinical laboratory (17). When the cause of higher rate of pre-analytic errors was investigated, the main reasons of errors in pathology unit were considered to be the carelessness of recording personnel as well as psychological burden due to being face to face with the patient constantly.

In our study, we predominantly tried the Six Sigma methodology in order to reduce the rate of errors in preanalytic and analytic phases because of the high number of errors assessed in these phases. This is a limitation of our study because this system could have also been applied for post-analytic errors including interpretation errors. Another limitation is the lack of the examination of the second review considerations of the consulted cases that were initially reported in our institute. Hence the interobserver variability and the error rate of interpretation results (if present) could be detected. Unfortunately we were unable to reach the majority of the second review results because of the lack of guidelines regarding the interdepartmental consultation protocols.

All of the mentioned errors in this study were recorded errors and it should be considered that unrecorded errors might also be present. This situation may depend on overlooking the errors or trying to solve the problems with direct relations without recording. However, checking the errors by recording through a transparent procedure should be the target for a pathology laboratory with a lower error rate. Finally, training and further studies regarding the implementation of this system in Turkey will provide more efficient pathology units with low error rates.

\section{ACKNOWLEDGMENTS}

The authors want to thank Yücel Duduoğlu for her time and technical support about the Six Sigma methodology in industry.

\section{REFERENCES}

1. Saquib N, Saquib J, Ahmed T, Khanam MA, Cullen MR. Cardiovascular diseases and type 2 diabetes in Bangladesh: A systematic review and meta-analysis of studies between 1995 and 2010. BMC Public Health. 2012;12:434.

2. Hollensead SC, Lockwood WB, Elin RJ. Errors in pathology and laboratory medicine: Consequences and prevention. J Surg Oncol. 2004;88:161-81.

3. Yorukoglu K, Uner S, Harorlu F, Usubutun A. Pathology laboratories productivity evaluation in Turkey. Turk Patoloji Derg. 2011;27:235-45.

4. Usubutun A, Balci S, Yorukoglu K. The situation of consultation practice in pathology in Turkey. Turk Patoloji Derg. 2012;28:195203.

5. Nakhleh RE. What is quality in surgical pathology? J Clin Pathol. 2006;59:669-72.

6. Caplinger J, Royse M, Martens J. Implementation of an oral care protocol to promote early detection and management of stomatitis. Clin J Oncol Nurs. 2010;14:799-802.

7. Nevalainen D, Berte L, Kraft C, Leigh E, Picaso L, Morgan T. Evaluating laboratory performance on quality indicators with the six Sigma scale. Arch Pathol Lab Med. 2000;124:516-9.

8. Nakhleh RE, Nosé V, Colasacco C, Fatheree LA, Lillemoe TJ, McCrory DC, Meier FA, Otis CN, Owens SR, Raab SS, Turner $\mathrm{RR}$, Ventura CB, Renshaw AA. Interpretive diagnostic error reduction in surgical pathology and cytology: Guideline from the College of American Pathologists Pathology and Laboratory Quality Center and the Association of Directors of Anatomic and Surgical Pathology. Arch Pathol Lab Med. 2016;140:29-40.

9. Aslan D, Demir S. Six sigma quality management in laboratory medicine. Turk J Biochem. 2005;30:272-8. 
10. Nakhleh RE. Error reduction in surgical pathology. Arch Pathol Lab Med. 2006;130:630-2.

11. Raab SS, Grzybicki DM, Mahood LK, Parwani AV, Kuan SF, Rao UN. Effectiveness of random and focused review in detecting surgical pathology error. Am J Clin Pathol. 2008;130:905-12.

12. Roy JE, Hunt JL. Detection and classification of diagnostic discrepancies (errors) in surgical pathology. Adv Anat Pathol. 2010;17:359-65.

13. Association of Directors of Anatomic and Surgical Pathology. Recommendations for quality assurance and improvement in surgical and autopsy pathology. Am J Surg Pathol. 2006;30:146971.
14. Recommendations on quality control and quality assurance in anatomic pathology. Association of Directors of Anatomic and Surgical Pathology. Am J Surg Pathol. 1991;15:1007-9.

15. Dhir R, Condel JN, Raab S. Identification and correction of errors in the anatomic pathology gross room. Pathology Case Reviews. 2005;10:79-81.

16. Pereira T, Silverman J. Anatomic pathology quality and safety monthly conference. Pathology Case Reviews. 2009;14:69-72.

17. Wiwanitkit V. Types and frequency of preanalytical mistakes in the first Thai ISO 9002:1994 certified clinical laboratory, a 6 month monitoring. BMC Clin Pathol. 2001;1:5. 